\title{
ASPECTOS ECONÔMICOS DA PRODUÇÃO DE BOVINOS DE CORTE ${ }^{1}$
}

\author{
Hilda Silva Araújo 2 , Omar Jorge Sabbag², \\ Bruno Tadeu Marotta Lima ${ }^{2}$, Cristiana Andrighetto ${ }^{2}$, Urbano dos Santos Ruiz ${ }^{2}$
}

\section{ABSTRACT}

\section{ECONOMIC ASPECTS OF BEEF CATTLE PRODUCTION}

Brazil is the world largest producer and exporter of beef, with its Middle West region accounting for 35\% of the national cattle killing, in 2010. However, it is necessary to value the planning, control, and business management in rural properties, aiming to profit from this activity. This study aimed to analyze and evaluate the economic viability of beef cattle production in Camapuã, Mato Grosso do Sul State, Brazil, in order to identify relevant items to the activity costs. As a guide of variable costs in the effective operational cost, the mineral supplement rationed to animals and labor were relevant to the management of the production system, representing approximately $71 \%$ of the costs. Based on the results, it was possible to conclude that the property shows a good profitability (above 20\%). Based on cash flows, it was observed an internal rate of return of $13.13 \%$ and that the initial capital returns in about 7 years, with attractive results for the investment in this agriculture segment. The study provided a cost parameter to cattle breeders, contributing to improve how activities are planned and how costs can be reduced, despite the high initial investment, with the rational management of the production system, which would be more attractive to the market, making its production activities and product commercialization more viable.

KEY-WORDS: Cattle breeding; production costs; economic viability.

\section{INTRODUÇÃO}

O Brasil ocupa, atualmente, as posições de maior produtor e maior exportador mundial de carne bovina, com rebanho de 176.610 .943 cabeças e produção de 1.700 mil toneladas equivalente-carcaça, destinadas à exportação, apresentando, ainda, consumo per capita de $38,7 \mathrm{~kg}$ pessoa $^{-1}$ ano $^{-1}$. O Estado de Mato Grosso do Sul tem grande importância, quanto à criação de bovinos de corte, possuindo rebanho de 16.811.912 cabeças (Anualpec 2010).

\section{RESUMO}

O Brasil ocupa as posições de maior produtor e exportador mundial de carne bovina, com a região Centro-Oeste respondendo por $35 \%$ do abate nacional, em 2010. Entretanto, faz-se necessário valorizar o planejamento, o controle e a gestão empresarial nas propriedades produtoras, visando ao lucro na atividade. O presente estudo objetivou analisar e avaliar a viabilidade econômica da produção de bovinos de corte, em Camapuã (MS), a fim de identificar os itens relevantes aos custos da atividade. Como direcionador dos custos variáveis, no custo operacional efetivo, o suplemento mineral fornecido aos animais e a mão de obra mostraram-se relevantes para a gestão do sistema de produção, representando, aproximadamente, $71 \%$ dos custos. Com base nos resultados apresentados, pôde-se concluir que a propriedade apresenta boa lucratividade (superior a 20\%). Verificou-se, ainda, com base no fluxo de caixa, taxa interna de retorno de $13,13 \%$ e capital inicial investido retornando em, aproximadamente, 7 anos, com resultados atrativos para o investimento, neste segmento agropecuário. $\mathrm{O}$ estudo proporcionou um parâmetro de custo para o produtor pecuarista, podendo contribuir para um melhor planejamento de atividades, em que, apesar dos altos investimentos iniciais, possivelmente, poderá reduzir seus custos, com o manejo racional no sistema produtivo, o que seria mais atrativo para o mercado, tornando mais viáveis as suas atividades de produção e comercialização do produto.

PALAVRAS-CHAVE: Pecuária; custos de produção; viabilidade econômica.

A região Centro-Oeste representou $35 \%$ do abate nacional, em 2010. Em termos de número de animais abatidos, o Estado de Mato Grosso mantém a liderança, tendo abatido $14,1 \%$ de toda a produção nacional feita pelos estabelecimentos fiscalizados, seguido pelos Estados de São Paulo e Mato Grosso do Sul, com 12,2\% e 10,7\%, respectivamente (IBGE 2010).

Atualmente, tem sido valorizado o planejamento, o controle e a gestão produtiva e empresarial, nas fazendas de pecuária de corte. Neste sentido, independentemente do sistema de produção utiliza-

1. Trabalho recebido em abr./2011 e aceito para publicação em mar./2012 (nº registro: PAT 13840).

2. Universidade Estadual Paulista (Unesp), Campus de Dracena, Departamento de Zootecnia, Dracena, SP, Brasil. E-mails: hil.araujo@bol.com.br, sabbag@dracena.unesp.br,bcidao@yahoo.com.br, cristiana@dracena.unesp.br, usruiz@dracena.unesp.br. 
do, o produtor sempre busca o lucro, seja reduzindo custos, aumentando a escala, trabalhando com vacas de maior produção ou utilizando sistemas mais rústicos. Qualquer que seja o sistema a ser utilizado, o produtor deve definir, primeiramente, seus objetivos e quais os recursos disponíveis. Após entrar na atividade, análises técnicas e financeiras devem ser continuamente refeitas, juntamente com simulações de diversas situações produtivas, para a tomada de decisões. A cada evento não previsto, o planejamento deve ser revisto (Carvalho et al. 2009).

Segundo Hoffmann et al. (1978), o objetivo mais importante dos registros, em uma empresa agrícola, sob o ponto de vista da administração, é a avaliação financeira e a determinação de seus lucros e prejuízos, durante determinado período. Esta avaliação fornece subsídios para diagnosticar a situação da empresa e realizar um planejamento eficaz, em relação aos custos.

Os custos fixos são aqueles que estão relacionados a fatores de produção que não podem ser modificados, em termos de quantidade utilizada, em curto período de tempo ou ciclo produtivo. Estes custos estão presentes na atividade, mesmo que a produção seja zero. No caso da depreciação, esta influencia diretamente na decisão de investimento, uma vez que ocorre a diminuição do valor de um bem, resultante do desgaste pelo uso, pela ação da natureza ou pela obsolescência normal (Freitas et al. 2007).

Os custos variáveis referem-se àquelas despesas relacionadas à utilização de insumos que podem ter suas quantidades variando em curto espaço de tempo, ou em um mesmo ciclo produtivo. Assim, o custo variável está relacionado com a quantidade produzida. São exemplos de custos variáveis as despesas com ração, medicamentos, mão de obra e fertilizantes.

Segundo Sabbag et al. (2007), fica evidenciada a necessidade de um agente responsável pela gerência, em uma das etapas da cadeia produtiva (neste caso, da pecuária bovina de corte, dentro de uma unidade de produção agropecuária), para garantir sua sobrevivência, destacando-se, sobretudo, a gestão de custos, como ponto fundamental para a viabilidade do agronegócio em questão.

Muitas vezes, por não conseguir controlar o preço do produto que vende, o produtor necessita administrar as variáveis que estão sob o seu controle. Trata-se de uma estratégia para tornar seu produto competitivo, atingindo menores custos de produção (Reis et al. 2001).
Dentre os instrumentos norteadores de decisão em investimentos, os mais utilizados são o payback, o Valor Presente Líquido (VPL) e a Taxa Interna de Retorno (TIR), desde que seja discutido um ponto fundamental nesta análise, que é a determinação da taxa de juros a ser utilizada (Taxa Mínima Atrativa de Retorno - TMAR) como parâmetro na avaliação econômica (Nogueira 2004).

Dessa forma, realizou-se a análise e a viabilidade econômica da produção de bovinos de corte, em uma propriedade em Camapuã (MS), identificando-se os itens relevantes dos custos na atividade, bem como os parâmetros relacionados à sua rentabilidade, fator fundamental para a obtenção da sustentabilidade na atividade e competitividade no setor.

\section{MATERIAL E MÉTODOS}

O caso estudado se caracteriza pela avaliação econômica de um sistema de produção atual, em uma propriedade de bovinos de corte localizada no município de Camapuã (MS), tomando-se, como base, a estrutura do capital já existente, receitas e dispêndios (custos e investimentos) ocorridos no ano de 2009, ou seja, com base em um corte no tempo.

$\mathrm{Na}$ propriedade, os animais são criados exclusivamente em pastagem extensiva, recebendo suplementação mineral durante todo o ano. O objetivo de produção é o ciclo completo, com base em um rebanho Nelore.

A fazenda possui área de pastagem de 784,5 ha, dos quais: a) 444 ha de Brachiaria brizantha cv. Marandú consorciada com Brachiaria dictioneura cv. Lllanero; b) 204 ha de Brachiaria brizantha cv. Marandú consorciada com Stylosanthes sp. Campo Grande; c) 136 ha de Brachiaria decumbens; d) 0,5 ha de capim Elefante (Pennisetum purpureum).

A propriedade possui uma sede, duas casas para funcionários, dois galpões e um centro de manejo (apartação, seringa, brete, tronco de contenção, balança mecânica e embarcadouro), com área de instalações e benfeitorias correspondendo a 3 ha.

O rebanho bovino é composto por 591 cabeças, das quais: a) 220 vacas, sendo 91 paridas e 129 solteiras; b) 51 bezerros e 40 bezerras até 7 meses; c) 70 novilhos e 50 novilhas até 18 meses; d) 52 novilhos para terminação no ano seguinte; e) 100 novilhos terminados durante o ano; f) 8 touros.

Dessa forma, o levantamento de custos constituiu-se em um método de avaliação de desempenho 
econômico e técnico da atividade produtiva em questão (Simões et al. 2006a).

A classificação dos custos foi feita conforme a proposta do Instituto de Economia Agrícola de São Paulo (IEA-SP), formulada por Matsunaga et al. (1976), na qual o custo operacional total compõe-se dos seguintes itens: operações mecanizadas, operações manuais, materiais, depreciações e encargos financeiros. Nas operações que refletem o sistema de cultivo (custo operacional efetivo), foram computados os materiais consumidos e o tempo necessário de máquinas e mão de obra, para a realização de cada operação, definindo-se, nestes dois casos, os coeficientes técnicos, em termos de hora máquina ${ }^{-1}$ e homem dia $^{-1}$. Os preços médios foram coletados na região, em unidade de Real (R\$), referentes a novembro de 2009.

O custo operacional total foi obtido pelo somatório dos seguintes itens:

Operações mecanizadas - Quantidade de combustível (óleo diesel) consumido (em litros) pelo trator, multiplicado pelo valor; lubrificantes: $20 \%$ do valor das despesas com óleo diesel; reparos e manutenção: $8 \%$ a.a. do valor inicial da máquina, dividido pelo número de horas que a máquina trabalha em um ano; tratorista: custo da hora (em R\$); abrigo: $1 \%$ a.a. do valor inicial da máquina, dividido pelo número de horas trabalhadas no ano; e seguro: $0,75 \%$ a.a. do valor inicial da máquina, dividido pelo número de horas trabalhadas no ano. A soma de todos estes gastos resultou no custo horário das operações mecanizadas;

Operações manuais - Foi realizado um levantamento das necessidades de mão de obra, nas diversas fases de produção, relacionando-se, para cada operação realizada, o número de homens dia $^{-1}$ (HD) para executá-la. Em seguida, multiplicaram-se os coeficientes técnicos de mão de obra pelo valor médio da região ( $\mathrm{R} \$ 30,00 \mathrm{dia}^{-1}$, para mão de obra comum);

Materiais - Os gastos com materiais referiram-se às despesas com concentrados, sal mineral, medicamentos, vacinas, etc. Estes gastos foram obtidos mediante o produto entre a quantidade dos materiais usados e os seus respectivos preços unitários;

Outras despesas - Considerou-se taxa de 5\% do total das despesas com insumos e operações mecanizadas e manuais;

Juros de custeio - Juros sobre as despesas de custeio, calculadas sobre $50 \%$ do custo operacional efetivo (COE), à taxa de $8,75 \%$ a.a;
Depreciação de máquinas e benfeitorias - As depreciações foram calculadas pelo método linear. Os indicadores de lucratividade utilizados no trabalho foram os considerados por Martin et al. (1997): a) Receita Bruta (RB): obtida multiplicando-se a produção pelo preço médio pago aos produtores; b) Lucro Operacional (LO): obtido através da diferença entre a receita bruta e os custos totais. Este indicador mede a lucratividade da atividade a curto prazo, mostrando as condições financeiras e operacionais da atividade agropecuária; c) Índice de Lucratividade (IL): proporção da receita bruta que se constitui em recursos disponíveis, após a cobertura do COT, através da expressão: $I L=L O / R B \times 100$.

Para a análise da viabilidade econômica do investimento, foi montado um fluxo de caixa, refletindo os valores das entradas e saídas dos recursos e produtos. A partir dos fluxos de caixa, foi determinada a TIR, que, por definição, é a taxa que torna o valor presente do fluxo líquido igual a zero, sendo calculada da seguinte forma:

$$
\sum{\stackrel{n}{t} L_{t=0}^{n}}_{(1+\rho)^{-t}}=0
$$

onde $\rho$ é a TIR, $L_{t}$ os fluxos líquidos de caixa e $t$ os períodos de produção da cultura, que variam de zero até $n$ (Noronha 1981). Ao se analisar um projeto por este método, o critério adotado é de que sua taxa interna de retorno seja igual ou superior ao custo de oportunidade do capital para a empresa.

Outro indicador usado para analisar a viabilidade econômica da produção de carne foi o Período de Recuperação do Capital (Pay Back Period), que estabelece o tempo necessário para a recuperação do investimento.

Neste trabalho, utilizou-se a metodologia de estudo de caso. A propriedade estudada foi escolhida pelo seu perfil tecnológico e padrão de controle zootécnico e gerencial, de modo que se aproximasse ao máximo da realidade encontrada na região, permitindo que os resultados encontrados tivessem parâmetros comparativos, para a referida região.

\section{RESULTADOS E DISCUSSÃO}

A estrutura de capital existente e os investimentos fixos necessários para a produção de bovinos de corte, em uma área de 784,5 hectares, encontram-se na Tabela 1. O valor total é da ordem de $\mathrm{R} \$ 859.819,00$, com destaque para os investimentos 
em capital fundiário e de exploração fixa (máquinas e implementos), que perfizeram $39,11 \%$ da estrutura da atividade.

Convém ressaltar que os recursos obtidos para a aquisição dos itens que compõem o investimento da atividade foram de cunho próprio, considerando-se apenas os juros de $8,75 \%$ a.a., para a manutenção (limpeza) de pastagens da pecuária bovina, permitido pelo programa Pronaf/Propasto - Resolução 2.856/2001 (Brasil 2001), caracterizando uma das etapas contidas nas operações mecanizadas (manutenção do ciclo produtivo), que resultaram, posteriormente, no custo operacional efetivo.

Para o custo de oportunidade da terra, foi considerado o valor de arrendamento das pastagens na região, para cinco anos de produção ( $\mathrm{R} \$ 25.417,80)$ (Tabela 1).
A estimativa de custo operacional efetivo e total de produção de bovinos de corte encontra-se na Tabela 2. O custo operacional efetivo (COE) foi de $\mathrm{R} \$ 63.722,29$. Salienta-se que os coeficientes técnicos de produção relacionados às operações mecanizadas (combustíveis e aluguel de trator) foram de R \$ 13.355,02, representando, aproximadamente, $20,9 \%$ do COE. Em 2009, o produtor reformou 48 ha de pastagem, pois tratava-se de uma área recém-adquirida, que encontrava-se degradada e necessitava de reforma urgente. As operações manuais, representadas pela mão de obra, referiram-se às principais atividades desempenhadas no sistema de produção em campo, como reforma e manutenção de pastagens, alimentação e manutenção do rebanho, dentre outros.

Os coeficientes foram extraídos por fase de criação no sistema, sendo especificado o número de

Tabela 1. Estrutura do capital existente e investimentos fixos para implantação e produção de bovinos de corte (Camapuã, MS, 2009).

\begin{tabular}{|c|c|c|c|c|}
\hline \multirow{2}{*}{ Item } & Quantidade & $\begin{array}{c}\text { Valor } \\
\text { unitário }\end{array}$ & $\begin{array}{l}\text { Valor } \\
\text { total }\end{array}$ & \multirow[t]{2}{*}{$\%$} \\
\hline & un. & \multicolumn{2}{|c|}{$\mathrm{R} \$$} & \\
\hline \multicolumn{5}{|l|}{ I- Capital fundiário } \\
\hline - Pastagem (ha) ${ }^{1}$ & 784,5 & 162,00 & $127.089,00$ & 14,78 \\
\hline - Projeto de georreferenciamento & 1 & $14.000,00$ & $14.000,00$ & 1,63 \\
\hline \multicolumn{5}{|l|}{ Benfeitorias: } \\
\hline - Galpão $40 \mathrm{~m}^{2}$ (armazenar ração e implementos)*** & 2 & $7.500,00$ & $15.000,00$ & 1,74 \\
\hline - Casa de funcionário $120 \mathrm{~m}^{2 * * *}$ & 2 & $26.250,00$ & $52.500,00$ & 6,11 \\
\hline - Sede $160 \mathrm{~m}^{2 * * *}$ & 1 & $70.000,00$ & $70.000,00$ & 8,14 \\
\hline \multicolumn{5}{|l|}{ II- Capital de exploração fixo** } \\
\hline \multicolumn{5}{|l|}{ Animais de reprodução e trabalho: } \\
\hline - Vacas & 220 & 850,00 & $187.000,00$ & 21,75 \\
\hline - Novilhas de até 18 meses & 50 & 600,00 & $30.000,00$ & 3,49 \\
\hline - Touros & 8 & $2.500,00$ & $20.000,00$ & 2,33 \\
\hline - Animais de trabalho (cavalos 1/2 Quarto de Milha) & 5 & $1.200,00$ & $6.000,00$ & 0,70 \\
\hline \multicolumn{5}{|l|}{ Máquinas e equipamentos: } \\
\hline - Veículo* & 1 & $25.000,00$ & $25.000,00$ & 2,91 \\
\hline - Trator* (Massey Ferguson 265, ano 1979) & 1 & $20.000,00$ & $20.000,00$ & 2,33 \\
\hline - Implementos trator** - arado de disco & 1 & $1.400,00$ & $1.400,00$ & 0,16 \\
\hline - Implementos trator** - arado de aiveca & 1 & $2.500,00$ & $2.500,00$ & 0,29 \\
\hline - Implementos trator** - sementeadeira & 1 & 750,00 & 750,00 & 0,09 \\
\hline - Tronco de contenção*** & 1 & $5.000,00$ & $5.000,00$ & 0,58 \\
\hline - Balança mecânica** & 1 & $3.000,00$ & $3.000,00$ & 0,35 \\
\hline \multicolumn{5}{|l|}{ III- Capital de exploração circulante } \\
\hline \multicolumn{5}{|l|}{ Animais para venda: } \\
\hline - Bezerros & 51 & 680,00 & $34.680,00$ & 4,03 \\
\hline - Bezerras & 40 & 480,00 & $19.200,00$ & 2,23 \\
\hline - Novilhos de até 18 meses & 70 & 770,00 & $53.900,00$ & 6,27 \\
\hline - Novilhos de até 24 meses & 52 & 900,00 & $46.800,00$ & 5,44 \\
\hline - Novilhos com 36 meses & 100 & $1.260,00$ & $126.000,00$ & 14,65 \\
\hline Total & & & $859.819,00$ & 100,00 \\
\hline
\end{tabular}


pessoas tarefa ${ }^{-1} \mathrm{e}$ a frequência de operações período ${ }^{-1}$ (considerando-se o ciclo anual de produção). Neste sentido, as despesas com mão de obra absorveram significativamente a atividade pecuária, representado aproximadamente $43 \%$ do COE.

Os insumos (materiais) utilizados no ciclo produtivo (vacinas, vermífugos, suplemento mineral e energia elétrica) refletiram diretamente em $36,4 \%$ do COE, reforçando que os maiores gastos foram atribuídos à suplementação animal.

Já o custo operacional total (COT) foi de $\mathrm{R} \$ 91.583,61$. Destacou-se a depreciação, referindo-se ao valor dos equipamentos exclusivamente depreciativos do sistema produtivo, conforme a Tabela 1 (valor inicial de R\$203.130,00, com valor residual correspondente, em relação ao tempo de vida útil específico, para cada item). Os demais itens agregados ao COE (encargos sociais, contribuição especial de seguridade social rural - CESSR, assistência técnica, despesas e encargos financeiros) são destacados a seguir, para melhor explicitar os valores obtidos para o COT, bem como a remuneração do investimento, para caracterizar o custo total de produção (CTP).

$\mathrm{O}$ custo total de produção (CTP), neste ciclo de produção completo, foi de $\mathrm{R} \$ 100.208,37$, resultante de um acréscimo significativo de $12 \%$ a.a., sobre o capital médio investido na atividade para cinco anos produtivos, representado pela remuneração ao capital fixo. O COT foi de R \$ 91.583,61, sendo composto por $\mathrm{R} \$ 10.019,95$ com depreciação, $\mathrm{R} \$ 8.969,40$ com mão de obra, $\mathrm{R}$ \$2.898,00 em encargos trabalhistas, $\mathrm{R} \$ 3.186,12$ com despesas gerais e R\$2.787,85 com encargos financeiros acrescidos ao COE (Tabela 2).

A receita bruta obtida por meio da venda de bovinos (100 animais que estavam em terminação) foi de $\mathrm{R} \$ 126.000,00$ (este valor representa diretamente a produtividade obtida, em relação ao preço médio

Tabela 2. Estimativa anual do custo operacional da produção de bovinos de corte (Camapuã, MS, 2009).

\begin{tabular}{|c|c|c|c|c|}
\hline \multirow{2}{*}{ Descrição } & \multirow{2}{*}{ Especificação } & Quantidade & Valor unitário & Total \\
\hline & & un. & \multicolumn{2}{|c|}{$\mathrm{R} \$$} \\
\hline \multicolumn{5}{|l|}{ A - Operações mecanizadas } \\
\hline Combustível - álcool & $\mathrm{L}$ & 300 & 2,65 & 795,00 \\
\hline Combustível - óleo diesel & $\mathrm{L}$ & 2400 & 1,90 & $4.560,00$ \\
\hline \multirow[t]{2}{*}{ Aluguel de trator } & $\mathrm{Ha}$ & 48 & 166,67 & $8.000,02$ \\
\hline & & & & $13.355,02$ \\
\hline \multicolumn{5}{|l|}{ B - Operações manuais } \\
\hline Capataz & $\mathrm{HH}$ & 1920 & 8,91 & $17.100,00$ \\
\hline \multirow[t]{2}{*}{ Peão polivalente } & $\mathrm{HH}$ & 1920 & 5,25 & $10.080,00$ \\
\hline & & & & $27.180,00$ \\
\hline \multicolumn{5}{|l|}{ C - Material (Insumos) } \\
\hline \multicolumn{5}{|l|}{ Vacinas: } \\
\hline Febre Aftosa & Dose & 1000 & 0,41 & 410,00 \\
\hline Antirábica & Dose & 500 & 0,30 & 150,00 \\
\hline Brucelose & Dose & 40 & 0,25 & 10,00 \\
\hline Clostridiose & Dose & 680 & 0,15 & 102,00 \\
\hline Vermífugo & Dose & 2925,23 & 1,20 & $3.510,28$ \\
\hline Fosbovi 15 & $\mathrm{SC}$ & 360 & 50,00 & $18.000,00$ \\
\hline \multirow[t]{2}{*}{ Energia elétrica } & $\mathrm{Kw} / \mathrm{h}$ & 3000 & 0,34 & $1.005,00$ \\
\hline & & & & $23.187,28$ \\
\hline Custo operacional efetivo (COE) & & & & $63.722,29$ \\
\hline Depreciação de máquinas e equipamentos & & & & $10.019,95$ \\
\hline Encargos sociais $^{1}$ & & & & $8.969,40$ \\
\hline $\mathrm{CESSR}^{2}$ & & & & $2.898,00$ \\
\hline Despesas gerais ${ }^{3}$ & & & & $3.186,12$ \\
\hline Encargos financeiros ${ }^{4}$ & & & & $2.787,85$ \\
\hline Custo operacional total (COT) & & & & $91.583,61$ \\
\hline Remuneração do capital & & & & $8.624,76$ \\
\hline Custo total de produção (CTP) & & & & $100.208,37$ \\
\hline
\end{tabular}


alcançado pelo pecuarista: $\mathrm{R} \$ 70,00$ arroba $\left.^{-1}\right)$, sendo caracterizada a venda de forma anual (Tabela 3 ).

A margem líquida (lucro operacional), obtida pela diferença entre a receita bruta e os custos totais, foi de $\mathrm{R} \$ 25.791,63$. Não existe retirada de pró-labore da propriedade e, desta forma, o lucro operacional possui o mesmo valor da renda líquida. $\mathrm{O}$ índice de lucratividade, que indica a proporção de receita bruta que se constitui em lucro após a cobertura dos custos, foi de $20,47 \%$, demonstrando que o sistema é lucrativo e viável, podendo, todavia, melhorar. Neste sentido, vale ressaltar que a lucratividade obtida mostrou-se superior, em relação a outros sistemas de exploração, como o do milho $(21,81 \%)$ e pecuária bovina leiteira (11,07\%), em pesquisas apontadas por Silva \& Machado (2001 apud Oliveira et al. 2004).

Entretanto, Mello Filho et al. (2005) calcularam os custos e indicadores econômicos de um sistema de cria-recria-engorda, no Estado de Rondônia, encontrando resultados positivos somente para

Tabela 3. Rentabilidade anual do custo operacional da produção de bovinos de corte (Camapuã, MS, 2009).

\begin{tabular}{lr}
\hline \multicolumn{1}{c}{ Discriminação } & Resultados \\
\hline Receita bruta (R\$) & $126.000,00$ \\
Custo total de produção (R\$) & $100.208,37$ \\
Lucro operacional (R\$) & $25.791,63$ \\
Preço médio @-1 $(\mathrm{R} \$)$ & 70,00 \\
Produção total (@) & 1.800 \\
Índice de lucratividade (\%) & 20,47 \\
Produção de equilíbrio (@) & 1431,55 \\
Preço de custo @-1 & $(\mathrm{R} \$)$ \\
\hline Fonte: dados da pesquisa. & 55,67 \\
\hline
\end{tabular}

o indicador margem bruta (considerando-se apenas o COE). Os indicadores econômicos que consideravam os custos indiretos, como depreciação e custo de oportunidade, foram negativos, mostrando que a atividade não foi sustentável a médio prazo e nem economicamente atrativa.

Da mesma forma, para equilibrar os custos totais de produção, a propriedade precisa vender, no mínimo, 1.431,55 arrobas ano ${ }^{-1}$, assim como vender ao valor mínimo de $\mathrm{R} \$ 55,67$ arroba $^{-1}$, para cobrir os custos totais de produção.

Para a análise de investimento (Tabela 4), durante os ciclos anuais de produção, verificaram-se resultados positivos para a produção, haja vista que o VPL é positivo (considerando-se o $10^{\circ}$ ano de produção), com TIR de $13,13 \%$, e o capital inicial investido retorna em, aproximadamente, 7 anos de produção. Na relação benefício/custo (IBC), verifica-se que há retorno de $85 \%$ para os produtores, em sua atividade. Ressalta-se que o IBC é um indicador relativo, medindo a expectativa de retorno para cada unidade de capital imobilizada no projeto.

$\mathrm{Na}$ análise da TIR, observa-se a viabilidade econômica do projeto, haja vista que a mesma foi superior à taxa mínima de atratividade (TMA), que, neste caso, foi de 6\% a.a. Desta forma, conforme retrata Kreuz et al. (2008), enquanto a TMA permanecer inferior à TIR, as expectativas são de que haja mais ganho em investir-se no projeto do que em deixar o dinheiro aplicado à TMA.

Diante dos resultados expostos neste trabalho, é compreensível a segurança da decisão de empreender na bovinocultura de corte, pois seria necessário que a

Tabela 4. Fluxo de caixa, valor presente líquido, TIR, relação B/C e Pay Back Period, para a produção de bovinos de corte (Camapuã, MS, 2009).

\begin{tabular}{|c|c|c|c|c|}
\hline \multirow{2}{*}{ Itens } & \multicolumn{4}{|c|}{ Anos } \\
\hline & 0 & 1 & 7 & 10 \\
\hline \multicolumn{5}{|l|}{ Saidas } \\
\hline Investimentos* $(\mathrm{R} \$)$ & $336.239,00$ & & & \\
\hline Custo operacional efetivo ciclo $^{-1}(\mathrm{R} \$)$ & $63.722,29$ & & & \\
\hline \multicolumn{5}{|l|}{ Entradas } \\
\hline Receita bruta $(\mathrm{R} \$)$ & $126.000,00$ & & & \\
\hline Fluxo líquido anual & $62.277,71$ & $62.277,71$ & $62.277,71$ & $62.277,71$ \\
\hline Fluxo líquido acumulado & & $149.405,87$ & $99.704,97$ & $286.538,10$ \\
\hline VPL $(\mathrm{R} \$)$ & & $169.769,94$ & $11.418,93$ & $122.130,37$ \\
\hline $\operatorname{TIR}(\%)$ & & $-24,48$ & 6,95 & 13,13 \\
\hline Pay Back Period & & & & 7 \\
\hline $\mathrm{B} / \mathrm{C}$ & & 0,56 & 1,30 & 1,85 \\
\hline
\end{tabular}


TMA (estimada em $6 \%$ a.a.) se alterasse para o valor da TIR apresentada $(6,95 \%$ a.a.), para que o mercado financeiro propiciasse o mesmo retorno, em 7 anos.

Costa (2000) apresentou dados da avaliação econômica, para um sistema de gado de corte de ciclo completo (cria-recria-engorda), na região de Campo Grande (MS), com taxa de retorno de capital de $6,24 \%$ a.a. De acordo com o autor, esta taxa pode variar conforme se altera a estratégia de venda dos animais e quando se desconsidera o valor do custo de oportunidade da terra.

Ainda assim, a TIR, no $10^{\circ}$ ano, foi superior à criação pecuária de alguns sistemas de criação, como Tupã (SP) (6,4\%) e Redenção (PA) (9,1\%) (Margulis 2003), situação que poderá ser potencializada, com base no esperado aumento de produtividade e na expectativa de estabilidade de preços, supondo-se que os aumentos dos custos de produção sejam recompensados pelo aumento da produtividade.

Em trabalho desenvolvido por Peres et al. (2004), as taxas encontradas foram favoráveis à adoção de qualquer sistema, pois foram superiores às remunerações obtidas em investimentos disponíveis no mercado, como a caderneta de poupança, por exemplo, cuja remuneração situou-se em torno de 6\% a.a, no mesmo período.

Simões et al. (2006b) fizeram uma análise comparativa da eficiência econômica de sistemas de produção de gado de corte, nas fases de cria, recria e engorda, na região de Aquidauana (MS), e observaram que todos os sistemas foram lucrativos. Entretanto, o perfil de composição dos custos e receitas da fase de engorda foi diferenciado do das demais fases, ressaltando que a atividade de engorda acaba sendo a mais competitiva, em termos de rentabilidade por hectare, e que estratégias de gestão diferenciadas devem ser adotadas, quando se analisam, comparativamente, os sistemas em questão, sobretudo com relação à redução do ciclo produtivo.

\section{CONSIDERAÇÕES FINAIS}

Este trabalho ofereceu um parâmetro de custo para o produtor pecuarista, podendo contribuir para um melhor planejamento de atividades, em que, apesar dos altos investimentos iniciais, possivelmente, poderá reduzir seus custos, com o manejo racional no sistema produtivo, o que seria mais atrativo para o mercado, tornando mais viáveis as suas atividades de produção e comercialização do produto.
Como direcionador dos custos variáveis no custo operacional efetivo, o suplemento mineral e a mão de obra tornam-se relevantes para a gestão do sistema de produção, representando, aproximadamente, $71 \%$ do COE. Na análise dos parâmetros relacionados à rentabilidade, observou-se índice de lucratividade de $20,47 \%$ (o que representa o valor agregado após a cobertura dos custos totais), podendo-se inferir que a propriedade apresenta uma boa rentabilidade na produção de bovinos de corte a pasto, bem como bom retorno do capital investido na atividade, a longo prazo.

\section{REFERÊNCIAS}

ANUALPEC 2010: anuário da pecuária brasileira. São Paulo: FNP, 2010.

BRASIL. Banco Central. Pronaf Propasto: encargos financeiros praticados. 2001. Disponível em: $<\mathrm{http}: / / \mathrm{www}$. bcb.gov.br/htms/creditorural/2001/encargos.pdf $>$. Acesso em: 14 mar. 2012

CARVALHO, F. M; RAMOS, E. O; LOPES, M. A. Análise comparativa dos custos de produção de duas propriedades leiteiras, no município de Unaí-MG, no período de 2003 e 2004. Ciência e Agrotecnologia, Lavras, v. 33. n. esp., 2009. Suplemento.

COSTA F. P. Avaliação econômica. In: MADUREIRA, L. D. Dia de campo: sistema de produção de carne com Nelore. Campo Grande: Embrapa-CNPGC, 2000.

FREITAS, L. C.; SILVA, M. L.; MACHADO, C. C. Influência do cálculo de depreciação no imposto de renda e no fluxo de caixa de uma atividade de transporte florestal. Revista Árvore, Viçosa, v. 31, n. 2, p. 257-264, 2007.

HOFFMANN, R. et al. Administração da empresa agrícola. São Paulo: Pioneira, 1978.

INSTITUTO BRASILEIRO DE GEOGRAFIA E ESTATÍSTICA (IBGE). Estatísticas da produção pecuária 2010. 2010. Disponível em: <http://www. ibge.gov.br/home/estatistica/indicadores/agropecuaria/ producaoagropecuaria/abate-leite-couro-ovos_201003 publ_completa.pdf $>$. Acesso em: 23 fev. 2011.

KREUZ, C. L; SOUZA, A.; CLEMENTE, A. Custos de produção, expectativas de retorno e de riscos do agronegócio mel no planalto norte de Santa Catarina. Custose@gronegócio on line, Recife, v. 4, n. 1, p. 4661, 2008.

MARGULIS, S. Causas do desmatamento da Amazônia brasileira. Brasília, DF: Banco Mundial, 2003. 
MARTIN, N. B. et al. Sistema "CUSTAGRI”: sistema integrado de custos agropecuários. São Paulo: IEA/SAA, 1997.

MATSUNAGA, M.; BEMELMANS, P. F.; TOLEDO, P. E. N. et al. Metodologia de custo utilizada pelo IEA. Agricultura em São Paulo, São Paulo, v. 23, n. 1, p. 12339, 1976.

MELLO FILHO, G. A. et al. Custo de produção de gado de corte no Estado de Rondônia. Campo Grande: EmbrapaCNPGC, 2005.

NOGUEIRA, M. P. Gestão de custos e avaliação de resultados: agricultura e pecuária. Bebedouro: Scot Consultoria, 2004.

NORONHA, J. F. Projetos agropecuários: administração financeira, orçamentação e avaliação econômica. São Paulo: Fundação Estudos Agrários Luiz de Queiroz, 1981.

OLIVEIRA, F. et al. Produção de mel na região noroeste do Estado de São Paulo: um estudo de caso de produtor familiar. Informações Econômicas, São Paulo, v. 34, n. 2, p. 15-24, 2004.

PERES, A. A. C. et al. Análise econômica de sistemas de produção a pasto para bovinos no município de Campos dos Goytacazes-RJ. Revista Brasileira de Zootecnia, Viçosa, v. 33, n. 6, p. 1557-1563, 2004.
REIS, R. P.; MEDEIROS, A. L.; MONTEIRO, L. A. Custos de produção da atividade leiteira na região sul de Minas Gerais. Organizações Rurais e Agroindustriais, Lavras, v. 3, n. 2, p. 45-52, 2001.

SABBAG, O. J. et al. Análise econômica da produção de tilápias (Oreochromis niloticus) em um modelo de propriedade associativista em Ilha Solteira/SP. Custos e @gronegócio on line, Recife, v. 3, n. 2, p. 86-100, 2007.

SIMÕES, A. R. P.; MOURA, A. D.; ROCHA, D. T. Avaliação econômica comparativa de sistemas de produção de gado de corte sob condições de risco no Mato Grosso do Sul. Revista de Economia e Agronegócio, Viçosa, v. 5, n. 1, p. 51-72, 2006a.

SIMÕES, A. R. P. et al. Avaliação econômica comparativa de sistemas de produção de gado de corte na região de Aquidauana/MS. In: CONGRESSO DA SOCIEDADE BRASILEIRA DE ECONOMIA E SOCIOLOGIA RURAL - SOBER, 44., 2006, Fortaleza. Anais... Fortaleza: UFC, $2006 \mathrm{~b}$. 